\title{
Auffüllen mit der „warmen Flasche“
}

\author{
Wie das Auffüllen der Harnblase vor einer suprapubischen Blasenfistelung möglichst schonend \\ gelingt, lesen Sie in folgendem Tipp.
}

Zu einer gefahrlosen suprapubischen Blasenfistelung gehört das möglichst schonende Auffüllen der Harnblase am ehesten über einen transurethral eingelegten Dauerkatheter. Nur so lässt sich erreichen, dass die Blase ohne Perforation des Peritoneums oder schlimmer von Peritonealinhalt punktiert werden kann. Besonders bei bereits länger transurethral abgeleiteten Patienten gestaltet sich das Erreichen der hierfür auch unter forensischen Gesichtspunkten erforderlichen Minimalfüllung der Blase von $300 \mathrm{ml}$ sogar manchmal in Sedoanalgesie schwierig. Hier hat sich in unserer Hand das Auffüllen mit einer „warmen Flasche“ bewährt:

Anstelle eines manuellen, eher groben Auffüllens der Blase mit einer Blasenspritze wird aus dem Vorrat der Anästhesie eine körperwarme Infusionsflasche mit einer Kochsalz- oder Elektrolytlösung mit dem Katheter verbunden (o Abb.1, - Abb.2) und die Blase tropfenweise schonend aufgefüllt. Eine intravesikale Druckerhöhung etwa durch eine instabile Detrusorkontraktion oder das Erreichen der anatomischen Blasenkapazität kann sofort am Sistieren der Tropfenfolge erkannt werden. Jede Infusionsflasche hat zusätzlich eine Graduierung, sodass die Menge der eingelaufenen Flüssigkeit zuverlässig bestimmt werden kann. Das Material ist in jedem TUR-Raum oder urologischen OP vorhanden und ermöglicht eine für den Patienten komplikationsarme und für den Operateur stressfreie Blasenfistelung.

\section{PD Dr. Andreas Wiedemann, Witten}

\section{Korrespondenz:}

PD Dr. Andreas Wiedemann

Urologische Klinik

Evangelisches Krankenhaus

im Diakoniewerk Ruhr gGmbH

Lehrstuhl für Geriatrie

der Universität Witten/Herdecke

Pferdebachstr. 27

58455 Witten

Tel.: +49/2302/175-2521

awiedemann@diakonie-ruhr.de

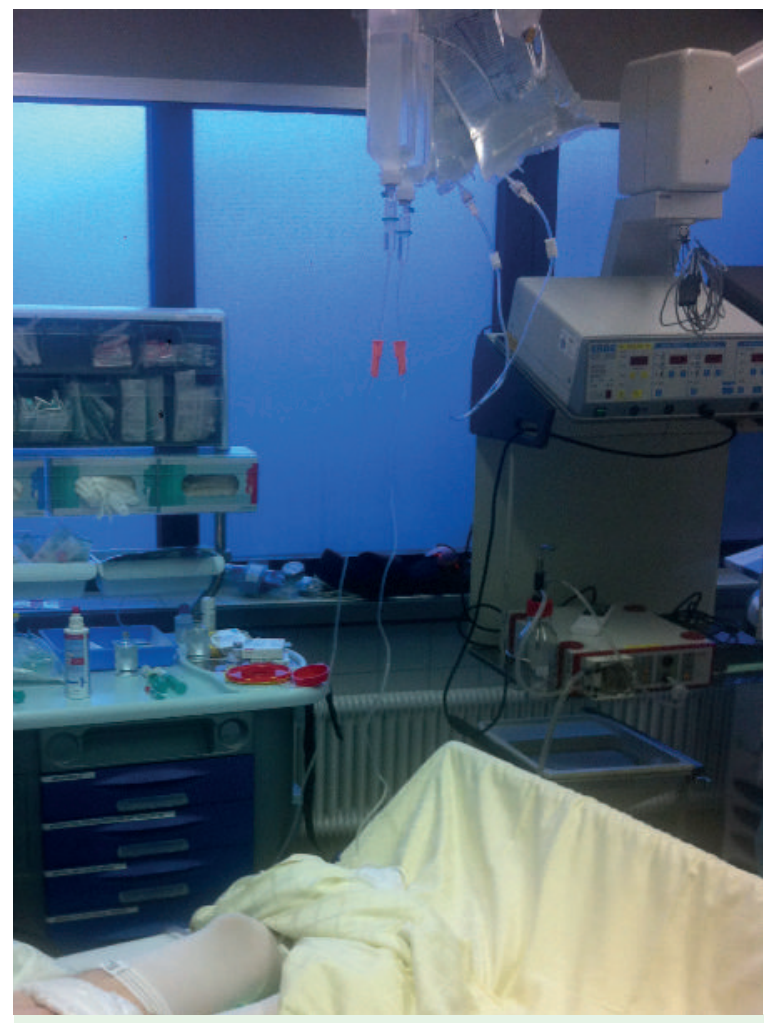

Abb.1 Eine Infusionsflasche dient wie gewohnt als intravenöse Infusion, eine weitere körperwarme Infusionsflasche dient zum Auffüllen der Harnblase vor Anlage des suprapubischen Katheters.

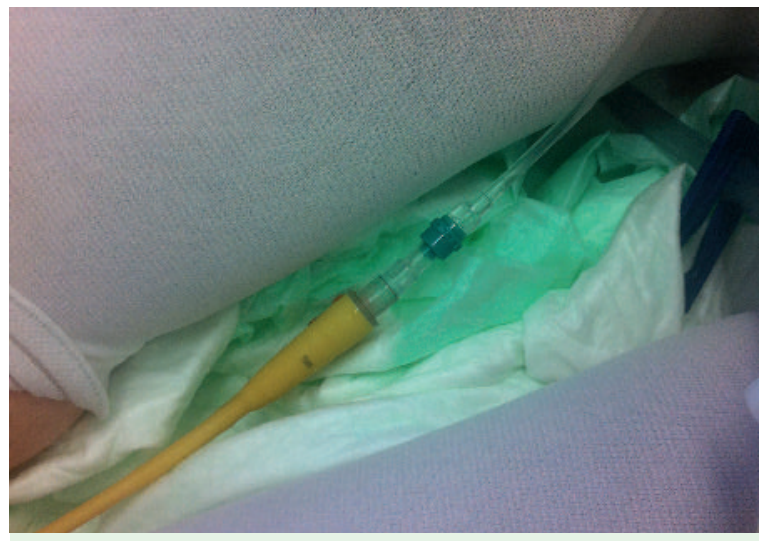

Abb.2 Das Infusionsbesteck der „warmen Flasche“ wird mit dem transurethralen Katheter zum langsamen, schonenden Auffüllen verbunden.

Interessenkonflikte:

Beratungstätigkeit: Dr. Pfleger, Pfizer; Vortragstätigkeit: Allergan, AMS Deutschland, Astellas, Berlin-Chemie, Janssen,
Lilly Deutschland, Dr. Pfleger, Pfizer, PohlBoskamp; Studienfinanzierung: AMS Deutschland 